\title{
Non-luminous Flame Gases
}

AFTer flame has travelled through a homogeneous inflammable mixture, the gases left behind ("flame gases') rapidly reach what is for all practical purposes a state of equilibrium. The flame gases (like ordinary open flames) are in general luminous, and their temperatures as determined by (i) calculation, (ii) fine platinum wires and (iii) quartz-covered platinum wires of the same overall diameter, differ by hundreds of degrees C. Typical temperature measurements made with combustible gas - air mixtures during the pre-pressure period in large closed-vessel explosions by means of wires of $0.0005 \mathrm{in}$. diameter are given in the accompanying table. We think that the explanation is that a proportion of the tri-atomic molecules formed during combustion holds in very stable fashion an excess of energy (probably in virtue of abnormal structure), and because of this an abnormal dissociation takes place, the products of which combine on the plain platinum surface ${ }^{1,2}$.

\begin{tabular}{lccc} 
& & \multicolumn{2}{c}{ Temperatures $\left({ }^{\circ} \mathrm{C}.\right)$} \\
Calculated & $\ldots$ & $28 \%$ Carbon monoxide & $9 \%$ \\
Platinum & $\ldots$ & 2110 & 1860 \\
Quartz .. & $\ldots$ & 1790 & 1680 \\
.. & 1440 & 1360
\end{tabular}

In the special case of inflammable mixtures with a very large excess of combustible gas, the abnormal dissociation appears to be suppressed in the flame gases, for the plain and quartz-covered wires yield exactly the same temperatures. These temperatures are far lower than the calculated temperatures ${ }^{1}$, and, of course, the flame gases are luminous. When, however, such mixtures undergo combustion in a tube, the flame gases, although luminous after the early stages of flame-front travel from the igniting spark, suddenly become non-Iuminous after further travel (due apparently to a sudden change in the mode of combustion in the flame front ${ }^{1}$ ). This rather remarkable phenomenon is vividly demonstrated in the flame photograph shown in Fig. 1, which was taken on a moving film during the explosion of a mixture (88 per cent carbon monoxide plus 12 per cent oxygen) in a glass tube.

We have recently completed a series of plain and quartz-covered wire temperature measurements with such mixtures in a closed iron tube $12 \mathrm{ft}$. in length and 4 in. in internal diameter. The wires were placed axially along the tube at various points up to $20 \mathrm{in}$. from the igniting spark. The results for a mixture (90 per cent carbon monoxide plus 10 per cent oxygen) are shown in Fig. 2. It will be seen that when the flame geses are luminous the wire tempera-

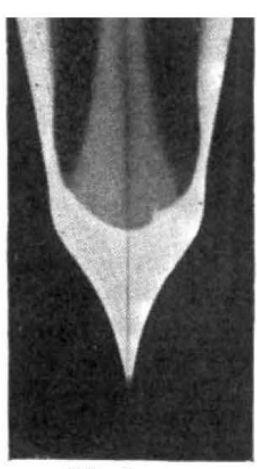

Fig. 1.

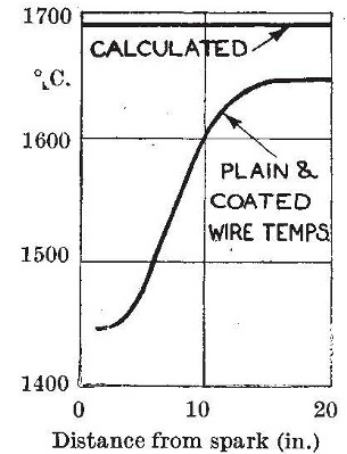

Fig. 2. tures are more than $200^{\circ} \mathrm{C}$. below the calculated temperature, whereas after $15 \mathrm{in.} \mathrm{(when} \mathrm{the} \mathrm{flame}$ gases are presumably non-luminous) they are much greater and are nearly equal to the calculated temperature indeed even more so than appears, for the wire temperatures are given as measured and have not been corrected for radiation loss either from the flame gases or from the wires. It would appear, therefore, that non-luminous flame gases, unlike ordinary flame gases, are just hot normal gases.

It may be of interest to point out that the flame photographs of Bone and Frazer suggest that nonluminous flame gases are also produced immediately after detonation is set up $^{3}$.

W. T. David.

J. MANN.

Engineering Department,

F. R. Mоввs.

University,

Leeds.

Jan. 2.

${ }^{1}$ Proc. Inst. Mech. Eng., 151, 236 (1.944) and other papers referred to therein.

${ }^{2}$ Phil. Mag., 34, 816 (1943)

${ }^{3}$ Phil. Trans. Roy. Soc., 230, 363 (1931), Photographs Nos. 5, 17, 22 and 32 .

\section{Effect of Length on Tensile Strength}

THE results of a large number of tension tests on nominally identical test pieces can conveniently be represented by a frequency curve in which the ordinate gives the frequency of occurrence of test pieces the strength of which is represented by the abscissa. The frequency of occurrence of test pieces the strength of which falls between the limits $x+d x$ and $x$ is given by $f(x) d x$. When the frequency curve is integrated with respect to $x$ and between the limits $-\infty$ and $x$, an integral curve is obtained the ordinate $F^{\prime}(x)$ of which gives the proportion of test pieces with strength less than $x$. The proportion of test pieces with strength greater than $x$ is given by I - F $F(x)$. Where the frequency curve does not depart greatly from normality, its characteristics can conveniently be summarized by its mean $(\mu)$, standard deviation $(\sigma)$ and skewness $\sqrt{\beta_{1}}$.

It is of interest to derive the distribution of strength of rods the length of which differs from those tested. Consider first the strength of rods which are $n$ times as long as those tested.

If the material is statistically homogeneous, such rods can be regarded as being composed of $n$ rods of unit length chosen at random and placed end to end. Fracture will occur when the breaking load of the weakest of the $n$ rods is reached. Owing to the predominance of low results, it would be expected that the mean strength would be lower and that the distribution would be more negatively skew than the distribution for the unit test pieces; and that the standard deviation would be lower. If $F_{1}(x)$ and $F n(x)$ are the probability integrals for the strength of test pieces of length 1 and $n$ units respectively, the distribution of the strength of the long test pieces is obtained by calculating the chance that $n$ unit test pieces chosen at random shall all be stronger than a given strength; for this is the chance that the weakest of $n$ test pieces shall exceed the given strength.

Thus $1-F n=\left(1-F_{1}\right)^{n}$. This result was given by Pierce ${ }^{1}$. 